\title{
Crescimento e acúmulo de nitrogênio em cana-de-açúcar cultivada em solo coberto com palhada ${ }^{(1)}$
}

\author{
Glauber José de Castro Gava ${ }^{(2)}$, Paulo Cesar Ocheuze Trivelin ${ }^{(3)}$, Mauro Wagner de Oliveira ${ }^{(4)}$ \\ e Claudimir Pedro Penatti(5)
}

\begin{abstract}
Resumo - Este trabalho teve o objetivo de avaliar a utilização do nitrogênio da uréia e a influência da palhada na produtividade de soqueira de cana-de-açúcar. $\mathrm{O}$ experimento foi instalado no campo, num solo Podzólico Vermelho-Amarelo no Município de Piracicaba, SP, com dois tratamentos: mistura de vinhaça e uréia aplicada em toda a área sobre o solo coberto com palhada; uréia enterrada em sulcos nos dois lados das linhas da cana-de-açúcar, com prévia aplicação de vinhaça sobre o solo sem palhada. $\mathrm{O}$ delineamento experimental foi o de blocos casualizados, com quatro repetições. Foram realizadas comparações de produtividade da cultura, do acúmulo de $\mathrm{N}$ pela parte aérea, da utilização do $\mathrm{N}$ da uréia pela cultura ao final do ciclo. O desenvolvimento vegetal foi representado por curvas de acúmulo de massa de material seco e pelos índices fisiológicos de taxa de produção de matéria seca e taxa de crescimento relativo, que foram semelhantes nas condições, com ou sem a presença da palhada de cana-de-açúcar. Do N total acumulado na parte aérea da soqueira de cana-de-açúcar, 10 a $16 \%$ foram absorvidos do fertilizante. A eficiência de utilização do $\mathrm{N}$ da uréia pela soqueira de cana foi em média de $17 \%$, e não houve diferenças entre os tratamentos.
\end{abstract}

Termos para indexação: Saccharum officinarum, soqueira, uréia, vinhaça.

\section{Growth and accumulation of nitrogen by sugarcane cultivated in soil covered with cane trash}

\begin{abstract}
The experiment was carried out to evaluate the use of nitrogen from urea and the influence of the cane trash in the productivity of sugarcane ratoon. It was a field experiment, in a Ustalfs soil, in Piracicaba, SP, Brazil, in October 1997, with two treatments: application of a vinasse-urea mixture in the total area of a soil covered with cane trash; and urea buried in furrows in both sides of the cane rows, with previous application of vinasse in a soil without cane trash. A randomized block design with four replications was used. Parameters of crop productivity accumulation of $\mathrm{N}$ by the top and use of urea $\mathrm{N}$ by the crop were evaluated in each treatment. Plant development was represented by a dry matter mass accumulation and by physiological indexes of dry matter production rate and relative growth rate, which were similar in both conditions, with and without cane trash. From the total N accumulated in the top of the sugarcane ratoon, $10-16 \%$ was absorbed from the fertilizer. The mean efficiency of the use of urea $\mathrm{N}$ by the sugarcane ratoon was $17 \%$.
\end{abstract}

Index terms: Saccharum officinarum, ratoon, urea, vinasse.

(1) Aceito para publicação em 27 de outubro de 2000.

(2) Universidade de São Paulo (USP), Centro de Energia Nuclear na Agricultura (Cena), Lab. de Isótopos Estáveis, Caixa Postal 96, CEP 13400-970 Piracicaba, SP. Bolsista da Fapesp. E-mail: ggava@cena.usp.br

(3)USP, Cena, Lab. de Isótopos Estáveis. Bolsista do CNPq E-mail: pcotrive@cena.usp.br

(4) Universidade Federal de Viçosa, Caixa Postal 342, CEP 35430-970 Ponte Nova, MG

E-mail: mwagner@mail.ufv.br

(5) Copersucar, Centro de Tecnologia Copersucar, Dep. de Solos, Caixa Postal 162, CEP 13400-870 Piracicaba, SP.

E-mail: claudimir@copersucar.com.br

\section{Introdução}

A análise do crescimento da cana-de-açúcar tem permitido avaliar os efeitos de diferentes formas de adubação e tratos culturais. Em um contexto mais geral pode ser estudada a produtividade de culturas em diferentes sistemas de produção. Esta análise do crescimento é realizada por meio de avaliações seqüenciais do acúmulo de fitomassa ou de índices fisiológicos dela obtidos.

Além da taxa de produção de matéria seca (TPMS), índice que avalia o crescimento do vegetal 
relacionando a quantidade de matéria seca acumulada, em razão da área de solo, por unidade de tempo, outro índice muito utilizado tem sido a taxa de crescimento relativo (TCR), que é definida como o aumento de matéria seca por unidade de matéria seca presente no início de determinado período experimental (Magalhães, 1979; Lucchesi, 1984; Beadle, 1987) e, tanto a TPMS quanto a TCR não requerem, para sua avaliação, conhecimento da área foliar da planta.

Considerando que a análise do crescimento é tida como método-padrão para se medir a produtividade biológica de uma cultura (Magalhães, 1979), seria interessante utilizar este método para avaliar os efeitos causados pela manutenção da palhada da canade-açúcar sobre o solo, no sistema de colheita sem prévia despalha a fogo, pois, nos últimos anos, nas diversas regiões canavieiras do centro-sul brasileiro tem havido aumento das áreas onde não mais se pratica a colheita da cana-de-açúcar com a queima prévia da palhada (Alvarez, 1998; Oliveira et al., 1999).

$\mathrm{Na}$ Austrália, a colheita mecanizada da cana-deaçúcar sem despalha a fogo vem sendo empregada de modo intensivo há mais de 15 anos, e, em regiões de solos com boa drenagem, os resultados são positivos (Wood, 1991). Em regiões canavieiras do Brasil e do mundo, onde a precipitação pluvial é pequena ou irregular, a presença da palhada sobre o solo também tem contribuído para elevar a produtividade da cana-de-açúcar (Ball-Coelho et al., 1993), principalmente por aumentar a infiltração da água no solo e diminuir a evaporação edáfica. Por outro lado, a presença da palhada na superfície do terreno dificulta o enterramento do adubo no solo, e, como a uréia tem sido o fertilizante nitrogenado mais utilizado na adubação da cana-de-açúcar, grandes perdas de amônia por volatilização podem ocorrer se este fertilizante for aplicado sobre a palhada.

Há possibilidade de se reduzirem as perdas por volatilização de amônia caso a uréia venha a ser aplicada juntamente com um doador de prótons. Assim, a vinhaça, um resíduo da indústria sucroalcooleira, que apresenta $\mathrm{pH}$ entre 3,2 e 5,1 e acidez titulável a pH 7,0, na faixa de 0,03 a $0,3 \mathrm{~mol} \mathrm{~L}^{-1} \mathrm{de}^{+}$(Rodella \& Ferrari, 1977), pode ser este doador de prótons.

Nos estudos de acúmulo de N pela cana-de-açúcar seria interessante quantificar a contribuição do $\mathrm{N}$ do fertilizante para a nutrição nitrogenada da cana- de-açúcar nesses dois sistemas de manejo. Utilizando-se a técnica isotópica com o traçador ${ }^{15} \mathrm{~N}$, é possível determinar esta contribuição através de microparcelas instaladas dentro de parcelas maiores (Trivelin et al., 1995, 1996).

O presente trabalho teve por objetivo avaliar a influência da palhada no crescimento da planta, na acumulação e utilização do $\mathrm{N}$ do fertilizante e na produtividade final da soqueira de cana-de-açúcar.

\section{Material e Métodos}

A área experimental consistiu de um talhão de canade-açúcar de cinco hectares, pertencente à Usina Iracema S/A, de Iracemápolis, SP.

A colheita mecanizada sem a despalha a fogo foi realizada no dia 10 de outubro de 1997, em área cultivada com a variedade SP 80-1842, no estágio de quarto corte (terceira soca), em solo classificado como Podzólico Vermelho-Amarelo, que apresentou na camada de 0-25 cm: $\mathrm{pH}\left(\mathrm{CaCl}_{2}\right) 4,6$; $\mathrm{P}$ (resina), 13,0 $\mathrm{mg} \mathrm{dm}^{-3}$; $\mathrm{K}, 5,1 \mathrm{mmol}_{\mathrm{c}} \mathrm{dm}^{-3} ; \mathrm{Ca}, 19,0 \mathrm{mmol}_{\mathrm{c}} \mathrm{dm}^{-3} ; \mathrm{Mg}$, $10,0 \mathrm{mmol}_{\mathrm{c}} \mathrm{dm}^{-3}$; CTC, 72,1 $\mathrm{mmol}_{\mathrm{c}} \mathrm{dm}^{-3} ; \mathrm{V}(\%), 47$, e uma composição em areia, silte e argila de 163, 249, $588 \mathrm{~g} \mathrm{~kg}^{-1}$, respectivamente.

O experimento teve duração de 315 dias. Nesse período, as médias das temperaturas máximas e mínimas foram, respectivamente, de 30,0 e $15,8^{\circ} \mathrm{C}$, e a precipitação pluvial no período totalizou $1.335 \mathrm{~mm}$.

O delineamento experimental foi o de blocos casualizados, com quatro repetições, e dois tratamentos: T1) mistura de vinhaça e uréia $\left(100 \mathrm{~m}^{3} \mathrm{ha}^{-1}\right.$ e $100 \mathrm{~kg} \mathrm{ha}^{-1}$ de $\mathrm{N}$, respectivamente), aplicada em área total sobre o solo coberto com palhada de cana-de-açúcar, contendo uma microparcela de 2,0 x 1,40 m, onde se aplicou uréia marcada com ${ }^{15} \mathrm{~N}$; T2) uréia enterrada em sulcos com $15 \mathrm{~cm}$ de profundidade distantes $25 \mathrm{~cm}$ dos dois lados das linhas da canade-açúcar (100 kg hä de N), com aplicação preliminar, feita no mesmo dia, de vinhaça $\left(100 \mathrm{~m}^{3} \mathrm{ha}^{-1}\right)$ sobre o solo sem palhada de cana-de-açúcar, contendo também uma microparcela $(2,0 \times 1,40 \mathrm{~m})$ onde se aplicou uréia marcada com ${ }^{15} \mathrm{~N}$.

A vinhaça aplicada ao solo apresentou, antes da adição de uréia, a seguinte composição química $\left(\mathrm{kg} \mathrm{m}^{-3}\right)$ : 0,41 de $\mathrm{N} ; 0,07$ de $\mathrm{P}_{2} \mathrm{O}_{5} ; 2,72$ de $\mathrm{K}_{2} \mathrm{O} ; 0,91$ de $\mathrm{CaO} ; 0,38$ de $\mathrm{MgO}$; e pH de 4,9. Após adição da uréia à vinhaça, a mistura elevou seu teor de $\mathrm{N}$ para $1,43 \mathrm{~kg} \mathrm{~m}^{-3}$. A uréia aplicada nas microparcelas dos tratamentos $\mathrm{T} 1$ e $\mathrm{T} 2$ apresentava abundância isotópica de $5,802 \%$ em átomos de ${ }^{15} \mathrm{~N}$. 
Os tratamentos T1 e T2 foram repetidos em cada bloco, para possibilitar a realização de amostragens mensais da fitomassa da parte aérea da soqueira de cana-de-açúcar. Assim foram realizadas avaliações mensais da produção de fitomassa da parte aérea da cana-de-açúcar, do terceiro mês após a adubação, ou 103 DAC (dias após o corte da soqueira), em janeiro de 1998, até o nono mês, ou 299 DAC (julho de 1998), em amostras coletadas em dois metros lineares.

Após a determinação da massa total de matéria fresca, em cada amostra foi retirada uma subamostra, depois de ter sido picada em triturador de forragem. As subamostras foram secadas em estufa de aeração forçada, com temperatura de $60-65^{\circ} \mathrm{C}$, até massa constante, e determinou-se a umidade do material fresco e o teor de $\mathrm{N}\left(\mathrm{g} \mathrm{kg}^{-1}\right)$ por digestão-destilação Kjeldahl. Com esses resultados, considerando existirem $7.143 \mathrm{~m}$ lineares de cana-de-açúcar num hectare, foram estimados a produção média da massa de material seco $\left(\mathrm{t} \mathrm{ha}^{-1}\right)$, e o $\mathrm{N}$ total acumulado $\left(\mathrm{kg} \mathrm{ha}^{-1}\right)$ na parte aérea da cana-de-açúcar, nos diferentes estádios de crescimento.

Do terceiro ao nono mês após a adubação, correspondentes ao período de 103 a 299 DAC, foram realizadas coletas mensais de folhas inteiras +3 (folhas com a terceira aurícula visível, segundo o sistema Kuijper) de plantas localizadas no metro central das microparcelas com uréia marcada com ${ }^{15} \mathrm{~N}$, dos tratamentos $\mathrm{T} 1 \mathrm{e} \mathrm{T} 2$, e em posições correspondentes nas linhas adjacentes às microparcelas (duas folhas por local). Essas amostras, após serem secadas em estufa e moídas em moinho tipo Willey com peneira de malha № 20 , tiveram a abundância de ${ }^{15} \mathrm{~N}$ (\% em átomos) determinada por espectrometria de massas (Trivelin et al., 1973), no espectrômetro de massas ATLAS CH-4. Esses valores serviram para estimar o N na planta proveniente do fertilizante (NPPF), segundo método adotado por Trivelin et al. (1994).

Para estimar o crescimento quantitativo da parte aérea nos tratamentos T1 e T2, durante o período experimental, utilizou-se a função logística: $\mathrm{Y}=\mathrm{Y}_{\max } /\left(1+(\mathrm{DAC} / \mathrm{A})^{\mathrm{B}}\right)$, em que: $Y$ é a matéria seca da parte aérea da soqueira em t ha- ${ }^{-1}$; DAC, dias após o corte da soqueira de cana-de-açúcar; $Y_{\max }$, matéria seca máxima produzida no período de 299 DAC.

As constantes A e B da função foram estimadas segundo Zullo \& Arruda (1987). Assim, foram obtidas duas equações que descreveram a variação, no tempo, da massa seca da parte aérea da soqueira de cana-de-açúcar a partir do 13ㅇ dia até os 299 DAC. Os índices fisiológicos utilizados para avaliar possíveis diferenças entre os tratamentos foram a taxa de produção de matéria seca e a taxa de crescimento relativo, obtidos pela manipulação das funções de ajuste, segundo modelo descrito por Lucchesi (1984).
A colheita final das microparcelas adubadas com ${ }^{15} \mathrm{~N}$ foi realizada de 16 a 18 de agosto de 1998 (315 DAC), segundo a metodologia definida por Trivelin et al. (1994).

As plantas foram divididas em amostras de folhas secas, colmo e ponteiro (folhas verdes, cartucho e palmito), das quais foi obtida, por pesagem, a massa de material fresco por tratamento. A umidade do material fresco, o teor de $\mathrm{N}\left(\mathrm{g} \mathrm{kg}^{-1}\right)$, determinado por digestão-destilação Kjeldahl, e a abundância de ${ }^{15} \mathrm{~N}$ (\% em átomos), determinada por espectrometria de massas (Trivelin et al., 1973), foram avaliados em subamostras obtidas das amostras totais, após serem passadas em triturador de forragem e secadas em estufa, de aeração forçada com temperatura igual a $60-65^{\circ} \mathrm{C}$, até massa constante.

Com os resultados de abundância isotópica de $\mathrm{N}$ $\left(\%\right.$ em átomos de $\left.{ }^{15} \mathrm{~N}\right)$, das amostras de folhas +3 das colheitas parciais e da parte aérea da cana-de-açúcar na colheita final, foi calculado NPPF (em \% e em kg ha-1), bem como a recuperação porcentual do $\mathrm{N}$ de fertilizante $(\mathrm{R})$, conforme Trivelin et al. (1994).

Os valores obtidos das variáveis de resposta foram submetidos à análise de variância, utilizando o teste $\mathrm{F}$, a 95\% de confiança. Quanto às causas de variação significativas, em que foi constatado efeito dos tratamentos, realizou-se o teste de Tukey a $5 \%$ de probabilidade.

\section{Resultados e Discussão}

\section{Acúmulo de material vegetal e de $\mathrm{N}$ e estimati- va da recuperação da uréia $\left({ }^{15} N\right)$ na soqueira de cana-de-açúcar}

No período de 103 a 299 DAC, o tratamento T2 mostrou média geral maior que o $\mathrm{T} 1 \mathrm{em}$ todos os parâmetros avaliados (Tabela 1). Esses resultados, todavia, indicam a possibilidade de a soqueira de cana-de-açúcar, sem a presença de palhada na superfície do solo, apresentar maior produtividade nas condições experimentais do trabalho, embora em cada estádio de crescimento as médias e o erro-padrão não indiquem efeito dos tratamentos na produção de massa de material fresco, seco, do $\mathrm{N}$ total e do $\mathrm{N}$ na planta proveniente do fertilizante, na parte aérea da soqueira de cana-de-açúcar.

Em experimento conduzido por Aude et al. (1993), verificou-se que a cobertura do solo por palhada de cana-de-açúcar teve efeito negativo sobre a produtividade da cultura. Entretanto, efeito positivo da presença de palhada sobre a produtividade da cana-de- 
açúcar foi relatado por Wood (1991) em relação a solos com boa taxa de drenagem, ou em regiões com precipitação pluvial insuficiente ou irregular. BallCoelho et al. (1993) observaram que a manutenção da palhada sobre o solo causou aumentos de $43 \%$ na produção de matéria seca da cana-de-açúcar.

As variações na produtividade da cana-de-açúcar em função da presença de cobertura do solo por palhada, verificadas na literatura, possivelmente estão relacionadas ao tempo de implantação do sistema sem queima, às condições termoídricas de cada região, à compactação do solo, e à variedade da canade-açúcar.

$\mathrm{O}$ acúmulo de $\mathrm{N}$ na parte aérea, nos dois tratamentos (Tabela 1), foi acompanhado por aumento de matéria seca até 169 DAC (março de 1998); posteriormente, decresceu ligeiramente no período de 204 a 237 DAC (abril a maio de 1998), e voltou a crescer entre 267 e 299 DAC (junho a julho de 1998) (Tabela 1). O acúmulo de matéria seca na parte aérea das plantas, no período posterior a 204 DAC, não se relacionou bem com o acúmulo de $\mathrm{N}$, pois enquanto nesse período houve incremento da ordem de $25 \%$ de matéria seca, no $\mathrm{N}$ o aumento foi superior a $80 \%$.

Trivelin et al. $(1995,1996)$ obtiveram resultados semelhantes aos deste experimento e levantaram a hipótese da translocação do $\mathrm{N}$ da parte aérea ao sistema radicular no começo da época de estiagem. Neste caso, em abril de 1998, a translocação provocaria o desenvolvimento do sistema radicular no período de 204 a 237 DAC. A emissão de novas raízes teria proporcionado maior exploração de volume de solo, aumentando, assim, o potencial de absorção e acúmulo de $\mathrm{N}$ do solo, observado no período de 267 a 299 DAC. Esse aumento na absorção de $\mathrm{N}$ mineral do solo, associado à menor volatilização do $\mathrm{N}$ pela

Tabela 1. Massa de material fresco e seco, $\mathrm{N}$ acumulado, $\mathrm{N}$ na planta proveniente do fertilizante (NPPF) e porcentagem de recuperação do $\mathrm{N}$ do fertilizante na parte aérea da soqueira (R), com (T1) e sem (T2) palhada sobre o solo, em diferentes períodos de dias após o último corte da soqueira (DAC), de cana-de-açúcar.

\begin{tabular}{|c|c|c|c|c|c|c|c|}
\hline DAC & Tratamento & $\begin{array}{c}\text { Material } \\
\text { fresco }\end{array}$ & $\begin{array}{l}\text { Material } \\
\text { seco }\end{array}$ & \multicolumn{2}{|c|}{ 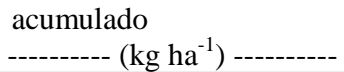 } & --------. & )------ \\
\hline \multirow[t]{2}{*}{103} & $\mathrm{~T} 1$ & 46 & 7 & 66 & 9 & 14 & 9 \\
\hline & $\mathrm{T} 2$ & 48 & 7 & 78 & 21 & 26 & 21 \\
\hline \multirow[t]{2}{*}{137} & $\mathrm{~T} 1$ & 69 & 13 & 88 & 12 & 14 & 12 \\
\hline & $\mathrm{T} 2$ & 74 & 15 & 100 & 28 & 28 & 28 \\
\hline \multirow[t]{2}{*}{169} & $\mathrm{~T} 1$ & 70 & 21 & 98 & 13 & 13 & 13 \\
\hline & $\mathrm{T} 2$ & 80 & 25 & 120 & 29 & 24 & 29 \\
\hline \multirow[t]{2}{*}{204} & $\mathrm{~T} 1$ & 84 & 22 & 816 & 10 & 12 & 10 \\
\hline & $\mathrm{T} 2$ & 91 & 26 & 95 & 23 & 24 & 23 \\
\hline \multirow[t]{2}{*}{237} & $\mathrm{~T} 1$ & 88 & 24 & 88 & 9 & 10 & 9 \\
\hline & $\mathrm{T} 2$ & 92 & 26 & 101 & 14 & 14 & 14 \\
\hline \multirow[t]{2}{*}{267} & $\mathrm{~T} 1$ & 94 & 25 & 144 & 14 & 10 & 14 \\
\hline & $\mathrm{T} 2$ & 97 & 29 & 153 & 24 & 15 & 24 \\
\hline \multirow[t]{2}{*}{299} & $\mathrm{~T} 1$ & 98 & 28 & 147 & 12 & 8 & 12 \\
\hline & $\mathrm{T} 2$ & 108 & 32 & 172 & 26 & 15 & 26 \\
\hline \multirow[t]{2}{*}{ Média $^{(1)}$} & $\mathrm{T} 1$ & $78 \mathrm{a}$ & $20 \mathrm{a}$ & $101 \mathrm{a}$ & $11 \mathrm{a}$ & $12 \mathrm{a}$ & $11 \mathrm{a}$ \\
\hline & $\mathrm{T} 2$ & $84 b$ & $23 b$ & $117 \mathrm{~b}$ & $24 b$ & $21 b$ & $24 b$ \\
\hline
\end{tabular}

${ }^{(1)}$ Médias seguidas de letras distintas diferem entre si pelo teste de Tukey a $5 \%$ de probabilidade. 
parte aérea, poderiam ser os fatores que contribuíram para maior taxa de acúmulo de $\mathrm{N}$ nesse período. Com a diminuição da temperatura, ocorreria também redução nas perdas gasosas de $\mathrm{N}$ pela folhagem, à semelhança do observado por Stutte \& Weiland (1978), levando, portanto, a maior acúmulo de $\mathrm{N}$ na parte aérea da planta.

Em todos os estádios de crescimento verificou-se que no tratamento $\mathrm{T} 1$, comparativamente a T2, houve tendência de menor acúmulo de $\mathrm{N}$ total, de $\mathrm{N}$ na planta derivado do fertilizante, e também na recuperação do $\mathrm{N}$ do fertilizante. Esses resultados poderiam ser atribuídos à maior imobilização microbiológica do $\mathrm{N}$ do fertilizante aplicado, por causa do aporte de palhada de elevada relação C:N (Vitti, 1998) e à maior volatilização do $\mathrm{N}$, pois nesse tratamento não se incorporou a uréia no solo (Kiehl, 1989).

Análise quantitativa do crescimento da soqueira de cana-de-açúcar no ciclo de 299 dias

Utilizou-se a função logística para calcular o acúmulo de matéria seca da parte aérea da soqueira, em diferentes estádios de crescimento (Figura 1), que foram assim descritos:

$\mathrm{Y}=28 /\left(1+(\mathrm{DAC} / 138,0693)^{-3,398)}\right.$ para o $\mathrm{T} 1$, $\mathrm{R}^{2}=0,98$, e $\mathrm{Y}=32 /\left(1+(\mathrm{DAC} / 139,1216)^{-3,510}\right)$ para o $\mathrm{T} 2, \mathrm{R}^{2}=0,94$.

A partir das equações anteriores, estimou-se a

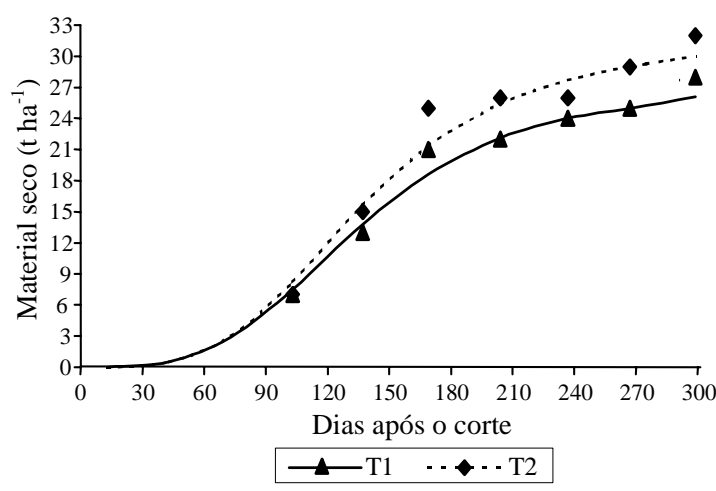

Figura 1. Acúmulo de material seco da parte aérea da soqueira de cana-de-açúcar em diferentes períodos representado pelos pontos, e o ajuste da função logística representado por linhas nas condições com (T1) e sem (T2) palhada sobre o solo. produção de matéria seca do vegetal, bem como os índices fisiológicos: taxa de crescimento relativo (TCR) e a taxa de produção de matéria seca (TPMS), segundo Lucchesi (1984), cujos resultados encontram-se na Figura 2. O acúmulo de matéria seca na parte aérea, nos dois tratamentos, apresentou uma forma sigmóide, característica de crescimento vegetal (Silveira, 1985), parecendo não haver influência positiva do resíduo vegetal adicionado ao solo. Tais resultados estão de acordo com os obtidos por Alvarez (1998), que não encontrou diferenças entre o crescimento de cana-de-açúcar com ou sem a presença de palhada, em dois ciclos vegetativos. Entretanto, por todo o período de crescimento monitorado, os valores médios foram constantemente maiores no tratamento $\mathrm{T} 2$.
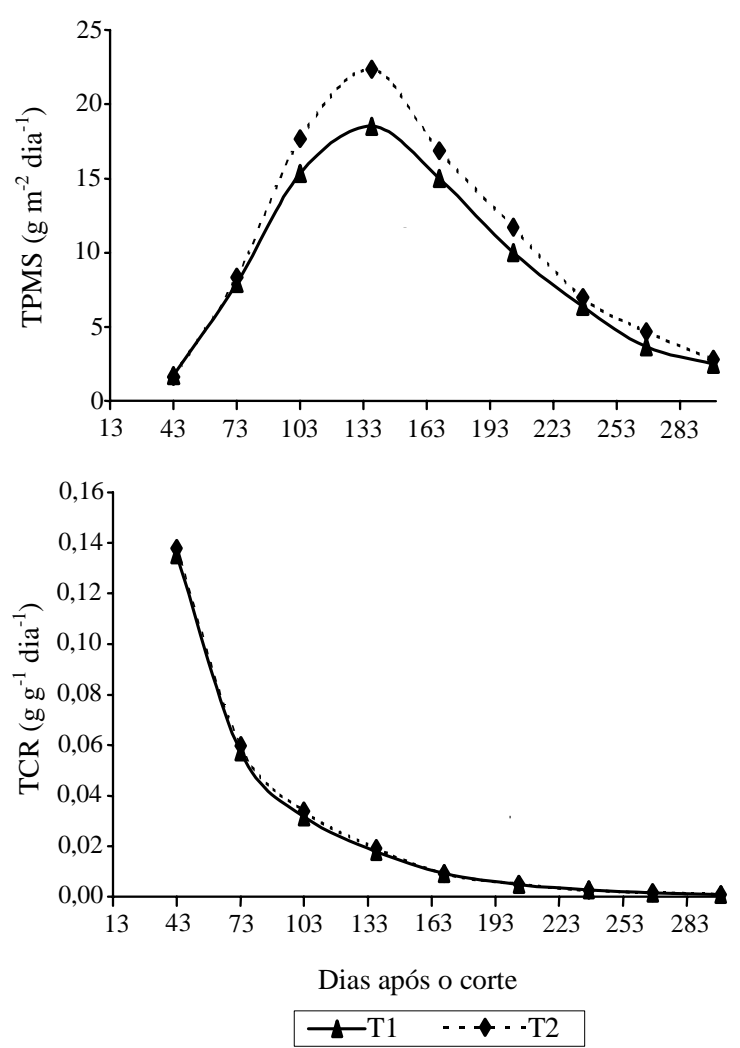

Figura 2. Taxa de produção de matéria seca (TPMS) e de crescimento relativo (TCR), da parte aérea de soqueira de cana-de-açúcar, com (T1) e sem (T2) palhada sobre o solo em diferentes períodos.

Pesq. agropec. bras., Brasília, v. 36, n. 11, p. 1347-1354, nov. 2001 
Os valores de acúmulo de matéria seca total nos dois tratamentos representam as três fases do desenvolvimento do vegetal (Figura 1), definidas por Machado (1987). Verifica-se que a primeira fase de desenvolvimento foi de 0 a 60 DAC, e o crescimento nesta época foi lento, e a planta acumulou cerca de $6 \%$ da matéria seca total contida na parte aérea. A segunda fase de desenvolvimento ocorreu no período de 60 a 210 DAC, quando a parte aérea da planta apresentou elevada taxa de crescimento, e acumulou, neste intervalo, $81 \%$ da matéria seca. A terceira fase, caracterizada como fase de maturação, ocorreu de 210 a 299 DAC, quando o acúmulo de matéria seca foi, em média, de $13 \%$.

A TPMS apresentou uma curva com formato de sino, nos dois tratamentos, foi baixa no início do ciclo, e aumentou rapidamente, até atingir um valor máximo, para, em seguida, decrescer (Figura 2).

Nos dois tratamentos, a máxima TPMS ocorreu aos 137 DAC (fevereiro). No tratamento T2, a TPMS máxima foi de $22,4 \mathrm{~g} \mathrm{~m}^{-2} \mathrm{dia}^{-1}$, e a média, de $11 \mathrm{~g} \mathrm{~m}^{-2} \mathrm{dia}^{-1}$, enquanto no T1 a TPMS máxima foi de $18,5 \mathrm{~g} \mathrm{~m}^{-2} \mathrm{dia}^{-1}$, e a média, de $7 \mathrm{~g} \mathrm{~m}^{-2} \mathrm{dia}^{-1}$. Estes resultados são semelhantes aos obtidos por Machado et al. (1982), que obtiveram TPMS máxima de $25 \mathrm{~g} \mathrm{~m}^{-2} \mathrm{dia}^{-1}$, e média de $12 \mathrm{~g} \mathrm{~m}^{-2} \mathrm{dia}^{-1}$.

A variação da taxa relativa de crescimento (TCR) no tempo é representada por uma função exponencial negativa (Figura 2), com valor máximo nos dois tratamentos aos 43 DAC (novembro de 1997), decrescendo com o tempo e estabilizando-se aos 210 DAC (abril de 1998), no início da época de maturação. A TCR máxima durante o período de monitoramento foi de 0,137 e $0,135 \mathrm{~g} \mathrm{~g}^{-1} \mathrm{dia}^{-1}$ no T2 e no T1, respectivamente. A TCR média foi de $0,0288 \mathrm{~g} \mathrm{~g}^{-1} \mathrm{dia}^{-1}$ no tratamento $\mathrm{T} 2$ e $0,0279 \mathrm{~g} \mathrm{~g}^{-1} \mathrm{dia}^{-1}$ no $\mathrm{T} 1$, sendo portanto semelhantes.

Verifica-se que em ambos os tratamentos (Figura 2) a TCR diminuiu à medida que a planta cresceu, devido, dentre outros fatores, ao aumento de competição intraespecífica pelos principais fatores ambientais responsáveis pelo crescimento vegetal, tais como: luz, nutrientes, difusão de $\mathrm{CO}_{2}$ dentro do stand.

\section{Recuperação do $\mathbf{N}$ da uréia $\left({ }^{15} \mathrm{~N}\right)$ na parte aé- rea da soqueira de cana-de-açúcar na colheita fi-} nal

Os resultados dos tratamentos que receberam a uréia com $\mathrm{N}$ marcado não se mostraram diferentes pela análise da variância (Tabela 2). Entretanto, existiu tendência de menor recuperação do ${ }^{15} \mathrm{~N}$ quando se aplicou a mistura vinhaça e fertilizante sobre o solo em área total. As possíveis explicações para essa tendência de menor aproveitamento do $\mathrm{N}$ do fertilizante no tratamento T1 são: (a) o efeito da localização da fonte nitrogenada; a aplicação do fertilizante aplicado próximo ao sistema radicular da cultura em T2 apresentou maior eficiência de aproveitamento, se comparada à aplicação em área total; (b) o $\mathrm{N}$ aplicado permaneceu temporariamente imobilizado na biomassa microbiana, devido à maior atividade dos

Tabela 2. Massa de material fresco e seco, $\mathrm{N}$ acumulado, $\mathrm{N}$ na planta proveniente do fertilizante (NPPF), e porcentagem de recuperação do $\mathrm{N}$ do fertilizante na parte aérea da soqueira de cana-de-açúcar na colheita final (R), com (T1) e sem (T2) palhada sobre o solo.

\begin{tabular}{|c|c|c|c|c|c|c|}
\hline Tratamento & $\begin{array}{l}\text { Parte da } \\
\text { planta }^{(1)}\end{array}$ & $\begin{array}{c}\text { Material } \\
\text { fresco }\end{array}$ & $\begin{array}{l}\text { Material } \\
\text { seco }\end{array}$ & \multirow{2}{*}{\multicolumn{2}{|c|}{ acumulado $\left.\mathrm{kg} \mathrm{ha}^{-1}\right)$}} & $\mathrm{R}$ \\
\hline & & ----------- & )-------- & & & $(\%)$ \\
\hline \multirow[t]{4}{*}{$\mathrm{T} 1$} & Po & 19 & 4 & 43 & 4,1 & 4 \\
\hline & FS & 9 & 8 & 30 & 3,4 & 3 \\
\hline & Co & 67 & 20 & 59 & 5,9 & 6 \\
\hline & PT & 95 & 33 & 131 & 13,5 & 14 \\
\hline \multirow[t]{4}{*}{$\mathrm{T} 2$} & Po & 18 & 4 & 42 & 6,6 & 7 \\
\hline & FS & 9 & 8 & 27 & 4,8 & 5 \\
\hline & Co & 70 & 22 & 67 & 10,3 & 10 \\
\hline & PT & 96 & 34 & 137 & 21,7 & 22 \\
\hline
\end{tabular}

${ }^{(1)} \mathrm{Po}$ : ponteiro (folhas verdes + ponteiro + cartucho); FS: folhas secas; Co: colmo; PT: planta toda. 
microrganismos quimiorganotróficos no T1 (Siqueira $\&$ Franco, 1988), fato este que também proporcionou menor aproveitamento do $\mathrm{N}$ do fertilizante; c) a maior volatilização do $\mathrm{N}$ da uréia quando essa é aplicada sem ser incorporada no solo (Kiehl, 1989).

A quantidade do $\mathrm{N}$ da uréia presente na parte aérea da cana-de-açúcar representou, em média, 14 e $22 \mathrm{~kg} \mathrm{ha}^{-1}$, valores estes que corresponderam a uma eficiência de utilização do fertilizante de cerca de 14 e $22 \%$ do $\mathrm{N}$ do fertilizante aplicado em diferentes formas no solo, respectivamente no T1 e T2.

Os valores de recuperação ou de eficiência de utilização do fertilizante (R) são semelhantes aos obtidos por Takahashi (1967) em relação às diferentes condições climáticas a que foi submetida a cultura $(\mathrm{R}=27$ a $12 \%)$. Por outro lado, esses valores de eficiência de recuperação do fertilizante podem ser considerados baixos, se comparados com os de Trivelin et al. (1995), que obtiveram valores de aproximadamente $40 \%$, porém usando outra variedade de canade-açúcar em outro solo.

O N na planta proveniente do fertilizante (NPPF) representou, respectivamente, 10 e $16 \%$ do total acumulado na parte aérea na soqueira de cana-de-açúcar no T1 e T2. Estes valores mostraram-se concordantes com os de $12 \%$ obtidos por Carnaúba (1989), e aos de Trivelin et al. (1995, 1996), que observaram valores de 12 a $14 \%$ do $N$ total acumulado na parte aérea da soqueira de cana-de-açúcar. É importante ressaltar que todos os trabalhos mencionados foram conduzidos em condições de manejo convencional, ou seja, sem a presença da cobertura do solo por palhada.

Com base nos resultados da literatura e nos deste trabalho, pode-se afirmar que, em condições variadas de solo, clima e variedade de cana-de-açúcar, o $\mathrm{N}$ na planta proveniente do fertilizante (NPPF) representa uma pequena fração do $\mathrm{N}$ total acumulado na parte aérea da cultura. Assim, pode-se inferir que as principais fontes de $\mathrm{N}$ para a cana-de-açúcar são a mineralização da matéria orgânica nativa do solo e de resíduos vegetais ( $\mathrm{Ng}$ Kee Kwong et al., 1987; Chapman et al., 1992; Sampaio et al., 1995; Vitti, 1998), e a fixação biológica do $\mathrm{N}$ atmosférico por microrganismo (Lima et al., 1987; Urquiaga et al., 1992). Devem-se mencionar os efeitos que ocorrem no solo associados ao $\mathrm{N}$ do fertilizante, quando em presença de matéria orgânica fresca, como a pool substitution e priming effect que levaram Jenkinson et al. (1985) a propor o conceito do ANI (interação no solo do $\mathrm{N}$ mineral adicionado). Em condições como as deste trabalho, pode ocorrer uma subestimativa na recuperação do $\mathrm{N}$ do fertilizante pela técnica com ${ }^{15} \mathrm{~N}$, e, como conseqüência, o aproveitamento do $\mathrm{N}$ de outras fontes é superestimado.

\section{Conclusões}

1. O acúmulo de massa de material seco e de $\mathrm{N}$ total nos diferentes estádios de crescimento e na colheita final da soqueira de cana-de-açúcar não são alterados pela cobertura da superfície do solo por palhada.

2. A palhada de cana-de-açúcar não altera a eficiência de utilização do $\mathrm{N}$ da uréia pela soqueira.

\section{Agradecimentos}

À Fapesp, pelo apoio financeiro; à Copersucar e à Usina Iracema $\mathrm{S} / \mathrm{A}$, pelo apoio logístico.

\section{Referências}

ALVAREZ, I. A. Comparação entre o desenvolvimento de cana crua e cana queimada em dois ciclos de crescimento. Piracicaba: Esalq, 1998. 116 p. Dissertação de Mestrado.

AUDE, M. I. S.; MARCHEZAN, E.; DARIVA, T.; PIGNATARO, I. H. B. Manejo do palhiço da cana-de-açúcar: 1. Efeito na produção de colmos industrializáveis e outras características agronômicas. Ciência Rural, Santa Maria, v. 23, n. 3, p. 281-286, 1993.

BALL-COELHO, B.; TIESSEN, H.; STEWART, J. W. B.; SALCEDO, I. H.; SAMPAIO, E. V. S. B. Residue management effects on sugarcane yield and soil properties in Northeastern Brazil. Agronomy Journal, Madison, v. 85, p. 1004-1008, 1993.

BEADLE, C. L. Plant growth analysis. In: COOMBS, J.; HALL, D. O.; LONG, S. P.; SCURLOCK, J. M. O. (Ed.). Techniques in bioproductivity and photosynthesis. 2 . ed. Oxford: Pergamon, 1987. p. 20-25.

CARNAÚBA, B. A. A. Eficiência de utilização e efeito residual da uréia - ${ }^{15} \mathrm{~N}$ em cana-de-açúcar (Saccharum spp.), em condições de campo. Piracicaba: Esalq, 1989. 193 p. Dissertação de Mestrado.

CHAPMAN, L. S.; HAYSOM, M. B. C.; SAFFIGNA, P.G. $\mathrm{N}$ cycling in cane fields from ${ }^{15} \mathrm{~N}$ labelled trash and residual fertilizer. In: AUSTRALIAN SOCIETY OF SUGAR CANE TECHNOLOGISTS CONGRESS, 14., 1992, Brisbane. Proceedings... Brisbane: Watson Ferguson, 1992. p. 84-89. 
JENKINSON, D. S.; FOX, R. A.; RAYNER, J. H. Interactions between fertilizer nitrogen and soil nitrogenthe so called "priming effect". Journal of Soil Science, Oxford, v. 36, p. 425-444, 1985.

KIEHL, J. C. Distribuição e retenção da amônia no solo após aplicação de uréia. Revista Brasileira de Ciência do Solo, Campinas, v. 13, p. 75-80, 1989.

LIMA, E.; BODDEY, R. M.; DÖBEREINER, J. Quantification of biological nitrogen fixation associated with sugar cane using a ${ }^{15} \mathrm{~N}$ aided nitrogen balance. Soil Biology \& Biochemistry, Oxford, v. 19, p. 165-170, 1987.

LUCCHESI, A. A. Utilização prática da análise de crescimento vegetal. Anais da Escola Superior de Agricultura Luiz de Queiroz, Piracicaba, v. 41, p. 181-201, 1984.

MACHADO, E. C. Fisiologia de produção de cana-deaçúcar. In: PARANHOS, S. B. (Coord.). Cana-de-açúcar: cultivo e utilização. Campinas: Fundação Cargill, 1987. v. 1, p. 56-87.

MACHADO, E. C.; PEREIRA, A. R.; FAHL, J. I.; ARRUDA, H. V.; CIONE, J. Índices biométricos de duas variedades de cana-de-açúcar. Pesquisa Agropecuária Brasileira, Brasília, v. 17, n. 9, p. 1323-1329, set. 1982.

MAGALHÃES, A. C. N. Análise quantitativa do crescimento. In: FERRI, M. G. (Ed.). Fisiologia vegetal. São Paulo: Edusp, 1979. v. 1, p. 331-349.

NG KEE KWONG K. F.; DEVILLE, J.; CAVALOT, P. C.; RIVIERE, V. Value of cane trash in nitrogen nutrition of sugarcane. Plant and Soil, Dordrecht, v. 102, p. 79-83, 1987.

OLIVEIRA, M. W.; TRIVELIN, P. C. O.; GAVA, G. J. C.; PENATTI, C. P. Degradação da palhada de cana-de-açúcar. Scientia Agricola, Piracicaba, v. 56, p. 803-809, 1999.

RODELLA, A. A.; FERRARI, S. R. A composição da vinhaça e efeitos de sua aplicação como fertilizante na cana-de-açúcar. Brasil Açucareiro, Rio de Janeiro, v. 90, n. 1, p. 380-387, 1977.

SAMPAIO, E. V. S. B.; SALCEDO, I. H.; SILVA, V. M.; ALVES, G. D. Capacidade de suprimento de nitrogênio e resposta à fertilização de vinte solos de Pernambuco. Revista Brasileira de Ciência do Solo, Campinas, v. 19, p. 269-279, 1995.

SILVEIRA, J. A. G. Interações entre assimilação de nitrogênio e o crescimento da cana-de-açúcar (Saccharum spp.) cultivada em condições de campo. Piracicaba: Esalq, 1985. 152 p. Tese de Doutorado.
SIQUEIRA, J. O.; FRANCO, A. A. Biotecnologia do solo: fundamentos e perspectivas. Brasília: MEC/Abeas/Esal/ Faepe, 1988. 236 p.

STUTTE, C. A.; WEILAND, R. T. Gaseous nitrogen loss and transpiration of several crop and weed species. Crop Science, Madison, v. 18, p. 887-889, 1978.

TAKAHASHI, D. T. Effect of amount and timing of the fate of fertilizer nitrogen in lysimeter studies with ${ }^{15} \mathrm{~N}$. Hawaiian Planters' Record, Honolulu, v. 57, n. 4, p. 292309, 1967.

TRIVELIN, P. C. O.; LARA CABEZAS, W. A. R.; VICTORIA, R. L.; REICHARDT, K. Evaluation of a ${ }^{15} \mathrm{~N}$ plot design for estimating plant recovery of fertilizer nitrogen applied to sugar cane. Scientia Agricola, Piracicaba, v. 51, n. 2, p. 226-234, 1994.

TRIVELIN, P. C. O.; RODRIGUES, J. C. S.; VICTORIA, R. L. Utilização por soqueira de cana-de-açúcar de início de safra do nitrogênio da aquamônia- ${ }^{-15} \mathrm{~N}$ e uréia- ${ }^{15} \mathrm{~N}$ aplicado ao solo em complemento à vinhaça. Pesquisa Agropecuária Brasileira, Brasília, v. 31, n. 2, p. 89-99, fev. 1996.

TRIVELIN, P. C. O.; SALATI, E.; MATSUI, E. Preparo de amostras para análise de ${ }^{15} \mathrm{~N}$ por espectrometria de massas. Piracicaba: USP, 1973. 41 p. (Cena. Boletim Técnico, 2).

TRIVELIN, P. C. O.; VICTORIA, R. L.; RODRIGUES, J. C. S. Aproveitamento por soqueira de cana-de-açúcar de final de safra do nitrogênio da aquamônia- ${ }^{15} \mathrm{~N}$ e uréia ${ }^{15} \mathrm{~N}$ aplicado ao solo em complemento à vinhaça. Pesquisa Agropecuária Brasileira, Brasília v. 30, n. 12, p. 1375-1385, dez. 1995.

URQUIAGA, S.; CRUZ, K. H. S.; BODDEY, R. M. Contribution of nitrogen fixation to sugar cane: nitrogen15 and nitrogen balance estimates. Soil Science Society of America Journal, Madison, v. 56, p. 105-114, 1992.

VITTI, A. C. Utilização pela cana-de-açúcar (cana-planta) do nitrogênio da uréia $\left({ }^{15} \mathrm{~N}\right)$ e do mineralizado no solo em sistemas de manejo com ou sem a queima. Piracicaba: USP-Cena, 1998. 93 p. Dissertação de Mestrado.

WOOD, A. W. Management of crop residues following green harvesting of sugarcane in North Queensland. Soil and Tillage Research, Amsterdam, v. 20, p. 69-85, 1991.

ZULLO, J. J.; ARRUDA, F. B. Programa computacional para ajuste de equações em dados experimentais. Campinas: Instituto Agronômico, 1987. 31 p. (Boletim Técnico, 113). 